\title{
Reflexiones sobre la pintura surrealista de Joan Miró (1923-1941)
}

YASUDA Keishi

\section{Introducción}

En la obra Fotomontaje del grupo surrealista, compuesta por el estadounidense Man Ray en 1934, se perfilan veinte surrealistas, que introdujeron nuevos aires en el arte de los años veinte y treinta. Este trabajo, en el que los artistas son descritos majestuosamente, simboliza la fuerza imparable del surrealismo en los primeros decenios del siglo XX. Además de André Breton, el francés que lideró este movimiento, se hallan otros artistas destacados y mundialmente conocidos, entre ellos tres españoles: Pablo Picasso, Salvador Dalí y Joan Miró, sobresaliendo este último por su mirada desafiante. ${ }^{1}$

Breton apuntó que la entrada de este pintor barcelonés en la escena surrealista en 1924 supuso un hito trascendental en la trayectoria de la pintura surrealista.' Esto quiere decir que Miró, al abordar varias formas de expresar el surrealismo, se destacó entre otros artistas de este movimiento.

Este estudio intenta analizar su pintura surrealista cronológicamente, en el período comprendido entre 1923 y 1941, y especular sobre el sentido de sus obras. Además tiene por objeto aclarar las características de su surrealismo.

\section{La irrupción en el mundo surrealista (1923-1927)}

Es necesario señalar que en 1923, un año antes de la fecha indicada por Breton, fue presentada La tierra arada, primera obra mironiana de tendencia surrealista. Miró, entre 1921 y 1922, había pintado La masía, que posteriormente sería adquirida por Ernest Hemingway, y ya había empezado a manifestar la abstracción de las formas de su cuadro. Desde 1919 Miró vivió en París y esta estancia en la capital francesa le condujo al surrealismo, que estaba 
en alza. Allí el pintor catalán se puso en contacto con los artistas dadaístas, que influyeron decisivamente en el surrealismo. Tanto La masía como La tierra arada se realizaron en este ambiente parisino.

En 1924, Miró conoció a André Breton. El mismo año éste publicó el Manifiesto del Surrealismo, que estipulaba la libertad en la creación artística, lo cual se difundiría en el ámbito de la literatura y de la pintura. Inspirado en este movimiento, Miró materializó El carnaval del arlequín, más surrealista que La tierra arada. Margit Rowell ha descrito El carnaval del arlequín como "una especie de repertorio de todos sus motivos, símbolos y signos, reagrupados en un mismo paisaje", y ha anotado que es el cuadro en que Miró se muestra más "surrealista", de acuerdo con las definiciones del movimiento. ${ }^{3)}$ De hecho, en comparación con La tierra arada, los rasgos de los animales parecen más abstractos. Pero, al mismo tiempo, este cuadro nos transmite una impresión alegre. Lucía García de Carpi explica este aspecto de la pintura de Miró como sigue:

"Miró recrea en sus obras un universo personal poblado de estrellas, notas musicales, escalas y diminutos animales. Un ámbito espacial sin dimensiones ni distancias, pero que, pese a su innegable arbitrariedad, nos resulta familiar."

Al abstraer las figuras, Miró no nos mantiene alejados de sus cuadros, sino que nos atrae con su "familiaridad". Este punto es la característica más significativa de su primera etapa surrealista.

Según Miró, El carnaval del arlequín denota "extraordinaria alegría a las alucinaciones provocadas por el hambre". ${ }^{5)}$ Por ello, es de suponer que en este cuadro se refleja el hambre del propio pintor catalán, ya que en aquella época se encontraba en la miseria y tenía serios problemas de alimentación. En una entrevista llevada a cabo en 1947, narraría esta situación:

"En esa época me mantenía con un puñado diario de higos secos. (...) El hambre era buena fuente de esas alucinaciones. Me sentaba largo rato mirando las paredes desnudas de mi estudio, intentando llevar esas formas 
al papel o a la arpillera (...).” ${ }^{6}$

Es sorprendente que un hombre sobreviviera comiendo a diario sólo higos secos. Tal vez con éstos nunca llegó a engañar el hambre. El carnaval del arlequín, según García de Carpi, se encuentra "entre lo mejor de su producción"." Resulta muy irónico e interesante que esta obra maestra naciera de esa circunstancia miserable que rodeó a Miró.

Sin embargo, el pintor catalán presentó en 1925 unas obras que no tenían nada que ver con El carnaval del arlequín. Especialmente los cuatro cuadros titulados Figura y los tres llamados Pintura nos causan una sensación de mayor sencillez que la pintura del año anterior, puesto que el número de figuras en todos estos cuadros es muy pequeño. Desde luego, en éstos no se ven ni "alegría" ni "familiaridad". Ese año Miró celebró su primera exposición personal en la Galerie Pierre de París. Aunque fue un acontecimiento comentado, no pudo ser un éxito comercial, debido a que los cuadros recientemente realizados carecían del impacto de las obras previas. En noviembre del mismo año, Breton promovió la exposición titulada "La Peinture surréaliste" y para ésta eligió El carnaval del arlequín como el cuadro más representativo de Miró. En 1926, la revista neoyorquina Little Review publicó un artículo sobre el pintor catalán y la obra utilizada para la ilustración fue La tierra arada, de $1923 .{ }^{\text {×) }}$ El interés público por Miró estaba en los cuadros del período entre 1923 y 1924.

Miró, ahora bien, no se preocupó de esta repercusión mediática y siguió materializando su pintura surrealista con total libertad, tal y como propugnaba el Manifiesto del Surrealismo. Entre 1926 y 1927 llevó a cabo dos obras, cuyos fondos y figuras se asemejan. Éstas son Perro que le ladra a la luna, en 1926 y Paisaje (La liebre), del año siguiente. La tierra y el cielo son casi idénticos en ambos cuadros; y lo mismo sucede con los motivos del perro y la liebre. Estas dos obras, muy sobrias de nuevo, proporcionaron un impacto mucho mayor que el de las obras de 1925.

Aquí lo que llama la atención es la existencia de la escalera en el extremo izquierdo de la primera obra. A este respecto, Umbro Apollonio ha explicado que la escalera tiene la función de "unir" dos mundos diferentes: tierra y cielo." 
Teniendo en cuenta esto, se deduce que el sol, que se acerca hacia la tierra en la otra obra, desempeña el mismo papel que dicha escalera. Es decir, Miró suprimió intencionadamente la distancia entre la tierra y el cielo mediante la puesta en escena de la escalera y el sol; y enfatizó que los dos pertenecían a la misma categoría: naturaleza. Al referirse a los cuadros de estos años, Miró afirmó que "la naturaleza irrumpe en lo fantástico". ${ }^{10 \prime}$ Así pintando la naturaleza, intentó aportar fantasía a sus cuadros. Esto era lo mismo que había hecho en La tierra arada y El carnaval del arlequín.

\section{Tras la estancia en Holanda (1928-1929)}

En la primavera de 1928 Miró hizo un viaje de unos quince días por los Países Bajos. Allí quedó fascinado por la pintura holandesa del siglo XVII, la cual sería de gran influencia en sus posteriores obras. El mismo año realizó una serie de cinco obras Interiores Holandeses. La más conocida de éstas es I. En este cuadro, se observa que Miró recuperó el dinamismo de El carnaval del arlequín. El número de las figuras aumenta y los perfiles de éstas salen trastocados. Rowell considera esta serie como "la síntesis de lo natural y lo fantástico, lo visible, lo real y lo imaginario"." En fin, aparte de los dos primeros elementos existentes en las obras mironianas hasta entonces, se añadieron otros tres. Sobre todo, "lo real" resulta de gran interés en el marco de la pintura surrealista.

Al pintar Interior Holandés I, Miró se inspiró en El tañedor de laúd (1661), de Hendrick Martensz Sorgh. ${ }^{12}$ En esta obra, un tañedor joven canta acompañándose con un laúd al lado de una mujer que lo escucha atentamente. En el suelo, se encuentran un perro y un gato. Estas cuatro figuras bastante corrientes fueron retratadas por Miró. "Lo real" de este cuadro mironiano provendría del hecho de que El tañedor de laúd fuera una obra barroca. En la práctica, estas figuras descritas por el pintor catalán quedan trastocadas, pero no pierden su forma original, lo cual supone "lo real" de Interior Holandés I .

Además, en consideración a la extensión del espacio donde se hallan las figuras, el tamaño del tañedor mironiano es colosal. Tomando una obra clásica como ejemplo, Miró se las ingenió al cambiar la talla del tañedor. Este aspecto trajo a su obra "lo visible" y "lo imaginario". En torno a esta serie mironiana, 
Rowell agrega que "son más densos y más sabios que El carnaval del arlequín". ${ }^{13)}$ A saber, fue un conjunto de obras en que Miró evidenció su inteligencia artística más que nunca.

Esta inteligencia de Miró se constata, asimismo, en algunas declaraciones de sus entrevistas. En una de ellas, refiriéndose a la dificultad para entender las figuras de sus obras, respondió así:

"Para mí, una forma nunca es algo abstracto; es siempre un signo de algo. Es siempre un hombre, un pájaro o cualquier otra cosa. Para mí, pintar no es nunca la forma por la forma (...)." ${ }^{14}$

El pintor catalán materializaba formas abstractas, pero nunca lo hacía "deliberadamente". Esta postura de Miró supone el "automatismo", considerado como uno de los elementos más fundamentales de la pintura surrealista. No obstante, en la misma entrevista, habló de que su actitud artística tenía poco que ver con el "automatismo":

"Un cuadro ha de ser milimétrico, ha de tener un equilibrio milimétrico." 151

De estas líneas, se entiende que Miró sabía controlar perfectamente el "automatismo" y la "meticulosidad" al mismo tiempo. Es decir, su "inteligencia" radicaba en la capacidad de equilibrar estos dos aspectos completamente contrarios. El pintor catalán llamó a esta "meticulosidad" "autodisciplina" ${ }^{16)}$ Aunque daba la sensación de que pintaba siempre libremente, en la práctica perfeccionaba sus obras tras unos procesos muy calculados.

La reina Luisa de Prusia, de 1929, sería el típico producto de su creación artística formada por el automatismo y la autodisciplina. Un cartel propagandístico de las motos de la empresa alemana Junkers le sugirió el tema de este cuadro. Miró, de esbozo en esbozo, convirtió el motor alemán en la reina prusiana. José Pierre la ha denominado como "una especie de diosamadre-máquina". ${ }^{17)}$ De esta heroína del cuadro, destaca lo grotesco de sus 
rasgos. Pero para Miró, el cambio brusco de la máquina a la reina no era nada raro, sino simplemente el resultado de su automatismo. El pintor catalán explicaría las formas simbólicas con los siguientes argumentos:

"Parecen elementos simbólicos, esotéricos, pero no son producto de la fantasía. Están ahí para equilibrar el cuadro." ${ }^{187}$

Miró siempre pensaba en el equilibrio de la obra. De ahí que se pueda considerar que la transformación de la máquina a la reina fue llevada a cabo por una búsqueda de armonía.

Examinando retrospectivamente los años veinte mironianos, Rowell los ha calificado de "un período rico y fecundo en el que Miró descubrió su sintaxis básica". Y ha añadido que esta sintaxis se radicaba en "una libertad aparentemente absoluta pero, sin embargo está regida por las leyes de una conciencia plástica". ${ }^{199}$ Su época más fructífera estaba totalmente sostenida por sus automatismo y autodisciplina.

\section{Gran cambio de estilo (1930-1935)}

En la primera mitad de los años treinta, la pintura surrealista de Miró experimentó una transformación notable. Sus cuadros perdieron su "familiaridad" y comenzaron a contar con perfiles "más agresivos y amenazadores". "2ó Lógicamente no le sentó nada bien a Breton, gran admirador de El carnaval del arlequín, que el pintor catalán presentara este viraje. El motivo del cambio provenía del rechazo a los artistas surrealistas que se comprometían en la acción política directa. Desde comienzos de la década de los treinta, el surrealismo, aparte de su creación artística, empezó a contar con otro objetivo: el compromiso político. De hecho, Breton fue miembro del Partido Comunista francés durante un breve período de tiempo. ${ }^{21}$ Miró, por otra parte, se distanció de esta corriente y materializó sus obras como una manifestación cultural, considerando que éstas eran "signo de todas las libertades y testimonio de aspiraciones a formas de elevada cultura" ${ }^{22)}$ Por eso, no es de extrañar que el pintor catalán comenzara a censurar la actitud de Breton, que "siempre buscaba detrás de una pintura «una idea»" ${ }^{23}$ 
Además, una nueva pobreza que asoló a Miró, aceleró su alejamiento de la sede del surrealismo. En 1933, debido a la falta de dinero, se vio obligado a dejar París y volver a Barcelona, su ciudad natal, por lo que siguió sus actividades artísticas en la casa de su madre. ${ }^{24}$ Los toques agresivos y amenazadores de sus obras de aquellos años también reflejaban la angustia por su miserable situación.

Este nuevo aspecto de los cuadros mironianos lo ejemplifica Mujer (1934). En esta obra, una señora, como protagonista, ocupa la mayor parte del lienzo. Pero tiene unos rasgos tan salvajes que no nos recuerdan a una mujer, sino a un monstruo. Y Miró empleó los colores negro, amarillo y rojo para pintarla, lo cual incrementó su impacto. Desde luego, en esta obra ya no se percibe, de ninguna manera, aquella "familiaridad" de El carnaval del arlequín. García de Carpi ha expuesto las características de la pintura surrealista mironiana de aquella época como sigue:

"Las figuras pierden la ligereza de antaño, siendo en ciertas ocasiones insólitamente pesadas, las atmósferas enrarecidas llegan a hacerse opresivas y el intenso colorido alcanza cotas de gran dramatismo." ${ }^{35 !}$

Está claro que Miró prefirió describir un ambiente mucho más angustioso que en sus etapas anteriores, lo que no estaba en consonancia con la más pura corriente surrealista. En Fotomontaje del grupo surrealista, la obra ya mencionada y realizada en 1934, el año que Miró pintó Mujer, éste aparece bastante lejos de Breton, en comparación con Picasso y Dalí, sus paisanos. Esta distancia con el líder francés pone de manifiesto su discordia con el grupo surrealista en aquellos años.

\section{Entre dos guerras (1936-1941)}

Hasta el otoño de 1936 Miró no efectuó la vuelta a París, aunque lo hizo forzosamente. ${ }^{26)}$ Fue por el estallido de la Guerra Civil española en julio del mismo año. En el momento del inicio de la contienda, el pintor catalán sintió "un profundo deseo de escapar" ${ }^{27)}$ Tras huir de la cruda realidad, se encerró en sí mismo y siguió pintando. Reflejando esta situación bélica de su patria, sus 
cuadros, como en la segunda mitad de la década anterior, volvieron a adquirir un matiz realista. En estos años, no sólo Miró sino otros artistas "surrealistas" españoles crearon obras "realistas". Picasso fue uno de ellos por su conocidísimo mural Guernica, de 1937. Este realismo contribuyó a revelar, siguiendo la expresión de García de Carpi, "todo el horror, toda la angustia y toda la violencia desatada a partir de 1936". ${ }^{28)}$

Al igual que Picasso, Miró también pintó un cuadro contra la contienda española en 1937. Como ha indicado Apollonio, esta obra, titulada Naturaleza muerta con zapato viejo, fue el "Guernica de Miró". ${ }^{29)}$ En ella, salen retratados una manzana, un trozo de pan, una botella de vino, un tenedor y un viejo zapato, pero todos están podridos y mohosos. ${ }^{301}$ El tono del cuadro nos causa un profundo desagrado transmitiendo la pesadez de la atmósfera. Se trata de la desastrosa escena de la guerra, en la que los comestibles y los artículos de primera necesidad no han podido desempeñar su función, y la fuerte repugnancia del autor a esta situación.

A pesar de que Miró apenas se atrevió con comentarios políticos, esta obra fue una clara manifestación de sus convicciones ante la contienda de su patria. Asimismo, este cuadro, por su tono realista, resulta mucho más fácil de entender que sus obras anteriores. Curiosamente en una entrevista llevada a cabo en París en 1936 cuando se inició la guerra de España, Miró dijo lo siguiente:

"Me parece vital que un tema rico y vigoroso se halle presente para dar al espectador un golpe directo entre los ojos antes de que pueda pensar en otra cosa." ${ }^{311}$

Con el motivo del comienzo de la contienda, el pintor catalán emprendió una orientación más realista. Esta decisión de Miró no sólo hizo comprender al espectador la circunstancia calamitosa de la guerra, sino que también posibilitó simultáneamente el darle un "golpe directo". Además, irónicamente este cuadro realista fue elogiado por Breton. ${ }^{321}$

Ese año, Miró materializó otra obra del mismo carácter: un cartel estampado para pedir apoyo a la República española. En éste, salen un eslogan 
en francés "Aidez l'Espagne" ("Ayudad a España”) y un robusto campesino catalán. Los ejemplares de este cartel se pusieron a la venta por un franco y el importe se asignó para la suscripción en favor de los republicanos en España. ${ }^{33}$ Esta actitud tan política de Miró simbolizaba esta etapa en la que situaba su realismo ante la contienda de su país en un primer plano.

Dos años después, sin embargo, se vio obligado a volver a enfrentarse a esta penosa situación de la guerra. En abril de 1939, el bando republicano, al que el pintor catalán apoyó, salió derrotado en la contienda española, y al cabo de cinco meses se inició la Segunda Guerra Mundial. Este acontecimiento le proporcionó la ocasión de vivir exiliado en Varengueville, cerca de la costa de Normandía. Esta escapada fue, según Apollonio, "una especie de retiro meditativo". " Claramente Miró se cansó de la circunstancia conflictiva tanto en su país como en el mundo.

Pese a su pésimo estado anímico, no perdió su entusiasmo creativo. Desde ese año, empezó a realizar una serie de cuadros Las Constelaciones, reconocida como una de sus obras maestras. La inspiración de esta serie derivaba del cielo. Ulteriormente Miró relataría que por las noches creó esta serie, y la música y las estrellas hicieron de papel sugerente fundamental para sus cuadros. ${ }^{35} \mathrm{Al}$ pintor catalán le gustaba la música clásica y solía escuchar a Bach y Mozart. Con esta música, mirando al cielo, materializó estas obras. A la hora de analizar esta serie, García de Carpi ha anotado lo siguiente:

"Miró, refugiado en Varengueville, demostró que el hombre, incluso en medio del horror, es capaz de mirar al cielo y escudriñar las estrellas, convirtiendo el motivo de la escalera de la evasión, frecuente en su obra, en un símbolo esperanzador." ${ }^{36)}$

A través de dicha serie, Miró pretendió plasmar una esperanza, que mucha gente había perdido sufriendo los desastres de la guerra. Sobre todo, unas obras de esta serie, realizadas entre 1940 y 1941, abundan en imaginación con un tono brillante, comparando con Naturaleza muerta con zapato viejo ante la Guerra Civil española.

Los cuadros de este bienio fueron en dirección contraria a las atrocidades 
bélicas y proporcionaron a los espectadores únicamente la esperanza como si hubieran neutralizado la cruda realidad a la que se enfrentaban. El canto del ruiseñor a medianoche y la lluvia matinal, la obra creada en 1940, fue alabada nuevamente por Breton. ${ }^{37)}$ Ciertamente la atmósfera de este cuadro nos recuerda la de El carnaval del arlequín, favorito del francés.

Irónicamente tras experimentar la trágica situación bélica, Miró reconquistó su fama como surrealista de los años pasados. Rowell define el bienio entre 1940 y 1941, en el que Miró se dedicó a Las Constelaciones junto con los años veinte, como "períodos privilegiados" ${ }^{38)}$ Aunque este segundo período terminó enseguida (tras su regreso a España en 1942 Miró empezó a tener interés por la cerámica y el grabado ${ }^{39}$ ), no hay ninguna duda de que alcanzó la cima de su surrealismo en este fugaz bienio.

\section{Conclusión}

En la primera mitad de los años veinte, Miró sustentó totalmente la corriente surrealista que Breton profesó. La razón radica en el hecho de que $E l$ carnaval del arlequín, obra maestra de esta época, fuera pintada en 1924 cuando Breton publicó el Manifiesto del Surrealismo. Además el elogio del francés, describiendo este cuadro como surrealista, certificaba la entrada de Miró en la escena de este género artístico.

El pintor catalán, no obstante, comenzó a interpretar el surrealismo a su manera y aportó nuevos aspectos a sus obras, a pesar de que este viraje molestó a Breton. Una de las características más relevantes de Miró fue su inteligencia que manejaba perfectamente no sólo hacia el automatismo, el elemento fundamental del surrealismo, sino también hacia la autodisciplina. En una entrevista en 1961, reflexionando sobre sus actos al realizar las obras, expresaría:

“Conoce la manera en que se preparan los arqueros japoneses para las competiciones? Comienzan por colocarse en cierto estado espiración, aspiración, espiración-y eso es lo que yo hacía. (...) Una debilidad, un error y todo colapsaría." ${ }^{40)}$ 
Como los arqueros nipones en el momento de disparar una flecha, Miró siempre se imponía con rigurosidad la costumbre de concentrarse durante sus actividades creativas. Esta concentración sostenía su inteligencia artística y mantenía su seria actitud ante sus obras.

Asimismo en dicha entrevista, el pintor catalán citó una "debilidad" o un "error" como "los que puedan colapsar el cuadro". Eso quiere decir que nunca se permitió mostrar ni "debilidad", ni "error" en sus obras. A principios de los años treinta, presentó unas expresiones más agresivas y amenazadoras que en sus etapas anteriores, pero verdaderamente no cometía errores, sino que era un cambio natural en su creación surrealista. Esta tendencia se daba también en la fase en la que realizó Naturaleza muerta con zapato viejo ante la conflagración interna de su patria. Es decir, este cuadro era, para él, "surrealista", pese al tono "realista". En la práctica, Miró recibió el elogio de Breton. De ello, se deduce que ante un tema bélico real seguía el vivo surrealismo en esta pintura de Miró, sin que éste mostrara ni fragilidad ni fallo con una postura "firme" y "seria".

Esta actitud no la cambió ante la Segunda Guerra Mundial. En este caso, en Las Constelaciones describió la esperanza con más aproximación surrealista. Esta serie suscitó, de nuevo, la alabanza de Breton, de ahí que proporcionara a Miró su segunda época "privilegiada". De este conjunto de obras, se perciben no sólo la esperanza, sino también la "familiaridad", que ya había demostrado en los años veinte. Así Miró, atravesando varias etapas diferentes, perfeccionó su pintura surrealista, que terminaría cristalizando en sus dos "períodos privilegiados".

\section{Notas}

1) En esta obra, aparte de Breton, Picasso, Dalí y Miró, figuran Max Ernst, Hans Arp, Yves Tanguy, René Char, René Crevel, Paul Eluard, Giorgio de Chirico, Alberto Giacometti, Tristan Izara, René Magritte, Victor Brauner, Benjamin Péret, Guy Rosey, E. T. Mosens, Georges Hugnet y el propio Man Ray.

2) García de Carpi, 1992, p.12.

3) Rowell, 1993, p.25.

4) García de Carpi, 1992, p.14.

5) Ibidem, p.14. 
6) Fragmento de JOHNSON SWEENEY, James, "Joan Miró: Comment and Interview”, Partisan Review (Boston), XV, 2 (febrero de 1948), pp.208-212, citado en Chipp, 1995, p.461.

7) García de Carpi, 1992, p.14.

8) Rowell, 1993, p.29.

9) Apollonio, 1970, p.37.

10) Rowell, 1993, p.27.

11) Ibidem, p.29.

12) Mink, 2000, p.50; Penrose, 1991, pp.58-59.

13) Rowell, 1993, p.29.

14) Johnson Sweeney, “Joan Miró...”, en Chipp, 1995, p.460.

15) Ibidem, p.460.

16) Ibidem, p.460.

17) Pierre, 1994, p.54.

18) Johnson Sweeney, “Joan Miró...”, en Chipp, 1995, p.460.

19) Rowell, 1993, p.31.

20) García de Carpi, 1992, p.14.

21) Bradley, 1999, p.55.

22) Apollonio, 1970, p.9.

23) Raillard, 1983, p.138.

24) Apollonio, 1970, p.9.

25) García de Carpi, 1992, p.14.

26) Apollonio, 1970, p.9.

27) Johnson Sweeney, “Joan Miró...”, en Chipp, 1995, p.463.

28) García de Carpi, 1994, p.40.

29) Apollonio, 1970, p.39.

30) Penrose, 1991, pp.86-87.

31) Fragmento de DUTHUIT, Georges, "Où allez-vous Miró?", Cahiers d'Art (París), XI, 8-10 (1936), p.261, citado en Chipp, 1995, p.460.

32) Pierre, 1994, p.57. Breton, refiriéndose a esta obra, declaró: “(...) me lleva a una filosofía especial sobre la inmanencia según la cual la propia realidad contiene el elemento surreal (...)" (Ibidem, p.57).

33) Penrose, 1991, p.89. Esta obra representa simbólicamente la repercusión internacional que provocó la contienda española, de manera que se ha utilizado como la portada del ensayo del escritor Fernando Schwartz (SCHWARTZ, Fernando, La internacionalización de la guerra civil española, Barcelona, Planeta, 
1999).

34) Apollonio, 1970, p.9.

35) Johnson Sweeney, “Joan Miró...”, en Chipp, 1995, p.461.

36) García de Carpi, 1992, p.15.

37) Penrose, 1991, pp.104-105. En esta ocasión, Breton escribió: "Nos permite introducirnos en el orden cósmico y penetrarlo con todo lo que implica el salirnos de los límites de nuestra humana condición" (Ibidem, p.105).

38) Rowell, 1993, p.31.

39) García de Carpi, 1992, p.17.

40) Entrevista con Rosamond Bernier, publicada en L'Oeil (París), julio-agosto de 1961, pp.258-259, citada en Rowell, 1993, p.37.

\section{Bibliografia}

APOLLONIO, Umbro, Miró, Barcelona, Ediciones Toray, 1970.

BRADLEY, Fiona, Surrealismo, Madrid. Ediciones Encuentro, 1999.

CHIPP, Herschel B., Teorías del arte contemporáneo, Madrid, Akal, 1995.

GARCÍA DE CARPI, Lucía, La pintura surrealista, Madrid, Historia 16, 1992.

-, "La respuesta española", en VV. AA., El surrealismo en España, Madrid, Museo Nacional Centro de Arte Reina Sofía, 1994, pp.21-44.

MINK, Janis, Miró, Colonia, Taschen, 2000.

PENROSE, Roland, Miró, Barcelona, Ediciones Destino, 1991.

PIERRE, José, "La contribución española a la revolución surrealista", en VV. AA., op.cit., pp.45-64.

RAILLARD, Georges, "El surrealismo arraigado de Miró", en BONET CORREA, Antonio (coord.), El Surrealismo, Madrid, Cátedra, 1983, pp.135-142.

ROWELL, Margit, “Joan Miró: Campo-Stella”, en Joan Miró: Campo de Estrellas, Madrid, Museo Nacional Centro de Arte Reina Sofía, 1993, pp.14-41. 
$<$ Resumen $>$

\section{Reflexiones sobre la pintura surrealista de Joan Miró (1923-1941)}

\section{YASUDA Keishi}

El surrealismo influyó decisivamente en el arte de los años veinte y treinta del siglo $\mathrm{XX}$. André Breton, el principal promotor francés de este movimiento, definió que la entrada de Joan Miró, pintor barcelonés, en esta corriente artística, convirtió la fuerza del surrealismo en "definitiva".

Miró, hasta que empezó a decantarse por la cerámica y el grabado en 1942, vivió cuatro etapas diferentes en el marco de la pintura surrealista. En la primera (1923-1927), expresó continuamente la "alegría", ejemplificada por El carnaval del arlequín (1924), una de las obras más relevantes de su carrera. Tras el viaje a Holanda, considerado como su segundo período (1928-1929), mostró en sus lienzos la influencia del arte flamenco del siglo XVII. No cabe duda de que su Interior Holandés I (1928) se parece a El tañedor de laúd, obra realizada por Hendrick Martensz Sorgh en 1661.

En la posterior tercera fase (1930-1935), la pintura mironiana experimentó un cambio drástico con unos toques "agresivos". Está claro que los cuadros de estos años, por ejemplo Mujer (1934), no expresan de ninguna manera la alegría de El carnaval del arlequín, lo cual provocó el desprecio de Breton, que era admirador de dicha obra. En lo referente a su cuarta y última etapa (1936-1941), Miró, inspirado en el contexto bélico que le rodeó (Guerra Civil española, Segunda Guerra Mundial), recuperó el estilo que había demostrado en su primer período surrealista; e intentó aportar a la gente la "esperanza" que había perdido. La serie Las Constelaciones (1940-1941), con un tono "brillante", fue una clara manifestación de ello.

Aunque contó con estas varias etapas, Miró siempre mantuvo el equilibrio entre la "autodisciplina" y el "automatismo", dos elementos totalmente opuestos. De ahí que culminara su pintura surrealista, sostenida por este balance minuciosamente cuidado. 